\title{
Eletricidade Atmosférica e Fenômenos Correlatos
}

\author{
Atmospheric electricity and correlated phenomenon \\ M. Tavares e M.A.M Santiago \\ Universidade Federal Fluminense \\ Instituto de Física, Av. Litorânea, s/n, \\ Boa Viagem, Niterói, \\ CEP 24210-340, Rio de Janeiro, Brasil
}

Recebido em 5 de novembro, 2001. Aceito em 20 de setembro, 2002.

\begin{abstract}
A qualquer momento, existem cerca de 2000 tempestades com relâmpagos nos céus em torno do mundo. Estima-se que as tempestades combinadas produzem aproximadamente 100 descargas de raios por segundo, cada uma com temperatura em torno de $30.000^{\circ} \mathrm{C}$ - mais quente que a superfície do Sol. Esse trabalho apresenta aos leitores alguns fenômenos elétricos na atmosfera e estratosfera. Tais eventos fazem parte de um sugerido circuito elétrico atmosférico global e estão conectados à pesquisa de plasmas. Atualmente o circuito elétrico atmosférico chama a atenção de cientistas pela importância de sua relação com o clima terrestre e seus efeitos em satélites e espaçonaves que devem atravessar a ionosfera.
\end{abstract}

\begin{abstract}
At any time, an estimated 2000 thunderstorms are lighting up the skies around the world. Combined, these storms produce approximately 10 lightning flashes per second, each one with a temperature of more than $30000^{\circ} \mathrm{C}$ - hotter than the surface of the Sun. This paper describes some facts and interesting events about lightnings and a different kind of phenomena what would occur in atmosphere and stratosphere. All these electrical phenomena make part of a suggested global electric circuit and are connected to plasma physics. Nowadays the electrical circuit has called attention of scientists by the importance that it would have for the terrestrial climate and for satellites and spaceships that should go through the ionosphere.
\end{abstract}

A presença da atmosfera onde ocorrem todos os fenômenos elétricos que vamos descrever não é a atmosfera original. Nossa atmosfera atual é o que os químicos chamariam de atmosfera com oxigênio enquanto a atmosfera anterior era o que os químicos chamariam uma atmosfera reduzida que não continha oxigênio. A atmosfera original seria muito semelhante em composição a de uma nebula solar ou da atmosfera atual dos planetas gigantes de gás. Teorias propõem que esta atmosfera foi perdida no espaço e substituída por compostos gasosos externos da crosta terrestre. Segundo teorias mais recentes, parte da nossa atmosfera é proveniente do impacto de cometas e outros asteróides ricos em material volátil. O oxigênio característico de nossa atmosfera foi quase todo produzido por plantas (cianobactérias ou as conhecidas algas azul esverdeadas). A composição atual da nossa atmosfera é $79 \%$ de nitrogênio, $20 \%$ de oxigênio e $1 \%$ de outros gases. Veja as camadas da atmosfera na Fig. 1.

A atmosfera da Terra é dividida em várias camadas, a mais inferior é a troposfera onde todo o clima acon- tece. A pressão do ar na parte superior da troposfera é cerca de $10 \%$ do nível do mar (0,1 atmosferas). Uma camada de cobertura entre a troposfera e a próxima camada é chamada de tropopausa. Acima da troposfera está a estratosfera onde o ar se propaga horizontalmente, uma fina camada de ozônio (é a forma reativa do oxigênio) situa-se na parte superior da estratosfera em alta concentração. Tal camada é responsável pela absorção de radiação ultravioleta do Sol. A formação dessa camada provém do oxigênio produzido na atmosfera. A camada de ozônio impede parte do intenso fluxo de radiação ultravioleta de alcançar a superfície terrestre onde seria prejudicial à evolução da vida.

Existe a preocupação de que compostos de fluorcarbonatos destruam a camada de ozônio gerando consequências ruins para a vida na Terra. Acima da estratosfera está a mesosfera e acima da mesosfera situa-se a ionosfera, onde muitos átomos são ionizados (ganham ou perdem elétrons) tendo carga elétrica própria (veja Fig. 1). A ionosfera é muito tênue mas é aí que a aurora se manifesta e também onde existe maior absorção de 
fótons do Sol. Nessa região a reflexão das ondas de rádio possibilita a comunicação a longa distância. Em adição ao circuito de corrente contínua, a atmosfera neutra entre a superfície da Terra e a ionosfera comporta-se como guia de onda quando excitada a frequência ultra baixa da radiação eletromagnética. Os elementos do espectro discreto das frequências de transmissão de 8 , $14,20, . . \mathrm{Hz}$ são chamadas ressonâncias de Schumann, propostas em 1952. Essas ressonâncias são excitadas por emissões eletromagnéticas provenientes das descargas dos relâmpagos e podem estar associadas às excitações de um circuito global de corrente alternada. $\mathrm{O}$ espectro de Schumann foi detectado por magnetômetros localizados em pontos remotos longe de interferência elétrica. As medidas feitas por tais aparelhos são armazenadas em super computadores. Nesses arquivos encontramos a variação do campo magnético da Terra e também do campo interplanetário, detectado e medido por satélites. Os fios no circuito global são basicamente feitos de ar ionizado. Exceção é o fio terra que é o próprio chão. Íons influenciam fortemente as propriedades elétricas da atmosfera, porque íons positivos e negativos podem ser separados um do outro produzindo campos elétricos de grande escala e porque sua presença no ar produz condutividade.

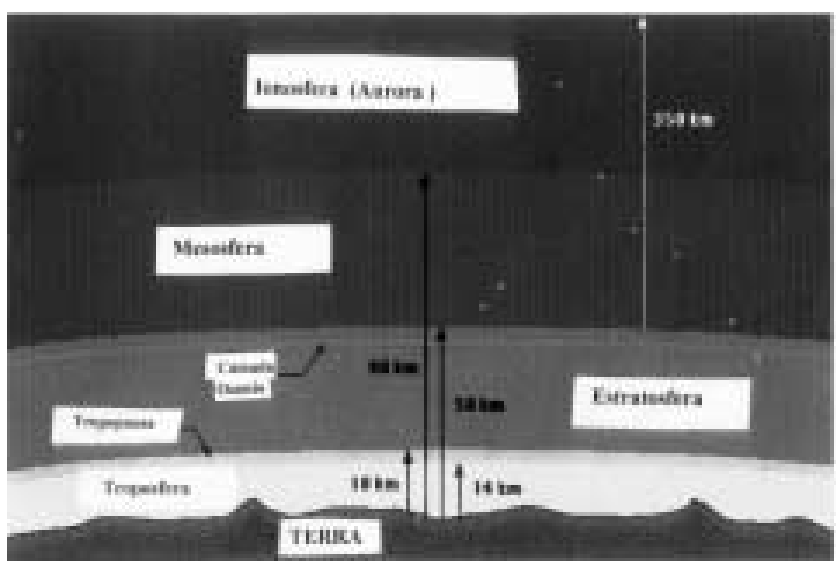

Figura 1. Camadas da atmosfera terrestre. A atmosfera terrestre tem sua camada mais próxima do solo como sendo troposfera, até $14 \mathrm{~km}$, uma fina camada entre a estratosfera e a troposfera chamada tropopausa, após a estratosfera temos a conhecida camada de ozônio, depois a ionosfera ou mesosfera onde ocorrem as auroras.

A estrutura da ionosfera é fortemente influenciada pelas partículas carregadas do vento solar que são comandadas pelo nível de atividade solar. Uma medida da estrutura da ionosfera é a densidade de elétrons livres, o qual indicará o nível de ionização. Como breve exemplo, tais partículas que entram na ionosfera e formam a aurora se manifestam próximas aos pólos terrestres. No entanto, em ocasiões onde ocorram grandes tempestades solares essas manifestações podem se dar próximas às regiões do equador. Um bom exemplo e atual foi o evento da aurora ocorrido em março de 2001 na Nova Zelândia. Como mencionado anteriormente,
2001 foi um ano de máximo solar. Abaixo da ionosfera, na atmosfera inferior (abaixo de $60 \mathrm{~km}$ ) o plasma não está em condições normais. Em cada metro cúbico de ar ao nível do mar a atmosfera normal contém $3 \times 10^{25}$ moléculas eletricamente neutras e apenas $5 \times 10^{8}$ íons. Cerca de $10^{7}$ pares de ions são criados por metro cúbico devido à radiação de ionização e um grande número é neutralizado pelo processo de recombinação. Quando partículas de poeira estão presentes, os íons leves são rapidamente absorvidos e os íons pesados de vida mais longa são criados. A ionização atmosférica no nível do mar sobre o solo é causada principalmente pelos raios gama emitidos por substâncias radioativas naturais. Os raios cósmicos também são uma grande fonte de ionização. Colisões entre raios cósmicos e moléculas neutras produzem moléculas carregadas positiva e negativamente, principalmente oxigênio e nitrogênio (na atmosfera densa, elétrons livres são quase inexistentes). $\mathrm{Na}$ atmosfera inferior o tempo de vida da recombinação para tais íons é tipicamente cinco minutos. Em poucos milissegundos os íons de $\mathrm{O}_{2}^{+/-}$e $\mathrm{N}_{2}^{+/-}$sofrem reações químicas e tornam-se hidratados com várias moléculas de água (tipicamente 6 a 8 moléculas e em temperaturas frias talvez 20 moléculas) para formar "pequenos íons" tais como $\mathrm{NO}_{3}^{-}\left(\mathrm{H}_{2} \mathrm{O}\right)_{8}$ ou $\mathrm{H}_{3} \mathrm{O}^{+}\left(\mathrm{H}_{2} \mathrm{O}\right)_{6}$. Na atmosfera inferior o tempo de vida da recombinação para esses íons é tipicamente cinco minutos. No caso dos aerossóis na atmosfera pequenos íons os atacarão, formando íons maiores, de qualquer forma reduzindo sua mobilidade atmosférica. Supõe- se que aerossóis aumentarão a quantidade de descargas elétricas na atmosfera. $\mathrm{Na}$ atmosfera, elétrons livres são imediatamente capturados por moléculas de oxigênio. Onde a poluição do ar é grande os íons leves são capturados pelas partículas pesadas de poeira criando íons pesados e menos móveis. A condutividade do ar poluído é dez vezes menor do que a do ar não poluído. O que vamos descrever a seguir são fenômenos elétricos na atmosfera e como devemos estudá-los com o conhecimento de física de plasmas. Sob a orientação da física de plasmas poderemos, [1], [2],[3],[4] sugerir modelos que nos forneçam a forma de explicar fenômenos atmosféricos elétricos.

\section{Correntes elétricas terrestres e relâmpagos}

Relâmpagos são manifestações elétricas da atmosfera. O relâmpago é também um fenômeno de plasmas. Lord Kelvin propôs que a ionosfera poderia ser considerada como a placa positiva de um capacitor esférico de potencial de $260 \mathrm{kV}$ com respeito à superfície da Terra, a qual seria a placa negativa. Hoje sabemos que tal capacitor descarrega através da atmosfera com corrente média de cerca de $1 \mathrm{kA}$ sobre a Terra. Três fontes quase diretas transferem força eletromotiva no circuito global: as tempestades, uma interação de dínamo entre 
o vento solar e a magnetosfera e o efeito dínamo decorrente na termosfera. As tempestades são consideradas as mais poderosas das fontes por um fator de três.

A corrente elétrica proveniente das tempestadas através da ionosfera é chamada de corrente de Wilson. Essa corrente se espalha sobre o globo através da ionosfera e da magnetosfera sobre as linhas de campo magnético para o hemisfério oposto. A corrente elétrica volta à superfície da Terra através da corrente que está presente com tempo bom. O processo global de correntes envolve várias camadas da atmosfera, descritas no parágrafo anterior. Tempestades e relâmpagos dependem do campo elétrico na atmosfera. $\mathrm{O}$ campo elétrico na atmosfera em condições normais é cerca de $100 \mathrm{~V} / \mathrm{m}$ apontando para baixo, o que é devido à carga negativa da Terra e à carga positiva na atmosfera. A condutividade elétrica na atmosfera aumenta com a altura. A atmosfera é um bom condutor cujos sinais variam lentamente na altitude de $50 \mathrm{~km}$, nível conhecido como sendo a eletrosfera. A reflexão das ondas de rádio vai ocorrer na região superior a $50 \mathrm{~km}$ da ionosfera. A voltagem entre a Terra e a eletrosfera está em torno de $3 \times 10^{5} \mathrm{~V}$. Para manter essa voltagem a Terra mantém carga negativa de cerca de $10^{6} \mathrm{C}$ na sua superfície, uma carga positiva igual está distribuída na atmosfera. Em regiões onde o tempo está bom, correntes atmosféricas de $10^{3}$ A estão continuamente anulando essa carga. As tempestades são uma espécie de bateria agindo para manter o sistema da atmosfera eletricamente carregado. Finalmente, vamos comentar porque não é possível usar relâmpagos como fonte de energia. Cada relâmpago da nuvem para o chão envolve uma energia na faixa de $10^{9}-10^{10}$ J. Se no mundo inteiro existem 100 descargas dirigidas para o solo por segundo e se toda a energia fosse capturada isso daria uma potência máxima de $10^{12} \mathrm{~W}$, um valor comparável ao máximo de potência elétrica consumida nos Estados Unidos no final dos anos 1980 , entre 0.5 e $0.6 \times 10^{12} \mathrm{~W}$. No entanto, existem dois problemas insolúveis. O primeiro é que muita energia é convertida em trovão, ar quente e ondas de rádio que até o presente momento não pode ser recuperada, sobrando uma pequena fração no canal de base para estocar ou usar de imediato. Segundo parece impraticável interceptar um relâmpago com torres altas ou esquemas semelhantes com qualquer quantidade significativa de energia da descarga. As técnicas para detecção de partículas dentro de nuvens têm sido aprimoradas através de missões de satélite como TRMM cujo instrumento LIS a bordo permite melhorar a definição dos tipos de partículas e estudo de descarga intra nuvens por exemplo. Todos os tipos de descargas não caracterizados como da nuvem para o chão são conhecidos como descargas das nuvens. É considerada uma descarga nas nuvens qualquer raio que não conecte com a Terra. Relâmpago é fenômeno transitório de descargas elétricas cujo comprimento da trajetória pode ser medido em quilômetros. A fonte mais comum para a ocorrência de um relâmpago é a separação de cargas elétricas em nuvens de chuva. As nuvens de chuva onde ocorrem relâmpagos se chamam Cumulonimbus. Uma descarga proveniente de nuvem típica transfere dezenas de coulombs sobre uma extensão total de $5-10 \mathrm{~km}$. A descrição de uma descarga consiste de um líder que se propaga continuamente gerando relâmpagos de retorno fracos que se associam a campos elétricos no interior das nuvens, (ver a Fig. 3). O tipo de relâmpago mais conhecido e de maior interesse prático é o relâmpago que se dirige para o solo, o conhecido raio ou descarga, que mata e fere animais, pessoas e árvores, perturba comunicações, redes elétricas e causa incêndios. Relâmpagos são facilmente fotografados e estudados através de instrumentos ópticos. Relâmpagos entre as nuvens e da nuvem para o ar são descargas menos comuns do que relampâgos intranuvem ou da nuvem para o chão. Um relâmpago vísivel começa com o aparecimento de um líder que se propaga através de um canal condutor de poucos centímetros de diâmetro que está no mesmo potencial que a base da nuvem. Consequentemente, com o deslocamento do líder para baixo e para fora da nuvem, o campo elétrico entre a extremidado do líder e o ar que o rodeia continuará a crescer e a ionização se torna mais fácil. Assim que o canal condutor entre nuvem e chão está completamente formado, a descarga principal se inicia. Em menos de 10 segundos uma corrente de 2000 A passa pelo canal de apenas alguns milímetros de diâmetro. A maior corrente detectada em um relâmpago foi de 345000 A. Na média cerca de $10^{9} \mathrm{~J}$ são liberados em um evento de descarga. A temperatura de um canal de relâmpagos, medida espectroscopicamente alcança $30.000^{\circ} \mathrm{K}$ em apenas $12 \mu \mathrm{s}$ após a passagem da descarga de retorno , mas decai rapidamente em cerca de $50 \mu \mathrm{s}$. O campo magnético associado à descarga é cerca de $1 \mathrm{~T}\left(=10^{4}\right.$ gauss $)$, assim o efeito "pinch" bem conhecido em plasmas pode ser importante nessa fase do relâmpago. Existem algumas teorias polêmicas sobre a importância dos relâmpagos no circuito global. Por exemplo, o circuito elétrico global integra a atividade global de tempestades dentro de variáveis determinadas pela temperatura média global da superfície terrestre e essas variáveis são muito mais sensíveis ao aquecimento global do que as medidas pela temperatura média global propriamente dita [13]. Essa idéia não foi provada, mas a lógica oculta é curiosa. Todo o aquecimento global na circulação atmosférica com o efeito estufa dá um crescimento na temperatura da superfície do planeta e decréscimo na temperatura da tropopausa, cuja combinação deverá ser desestabilizante. Durante o aquecimento global crescerá a energia na superfície tanto para o calor sensível do ar como para o calor latente do vapor d'água. A energia restante será liberada em atividade convectiva na nuvem. Outras perguntas associadas a relâmpagos ainda permanecem sem resposta. Como as nuvens têm suas cargas em camadas positivas e negativas? Qual a fonte dessas 
cargas? Que modelo matemático explicaria melhor as descargas das nuvens de tempestade? [1],[5],[6],[7].

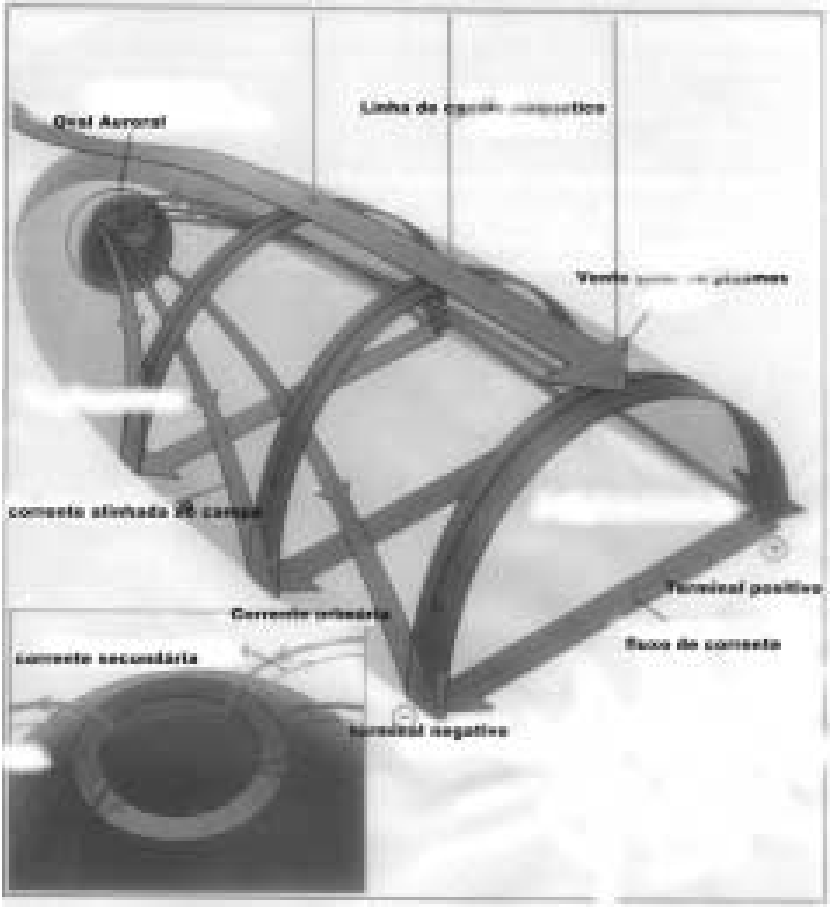

Figura 2. Circuito elétrico global da Terra.

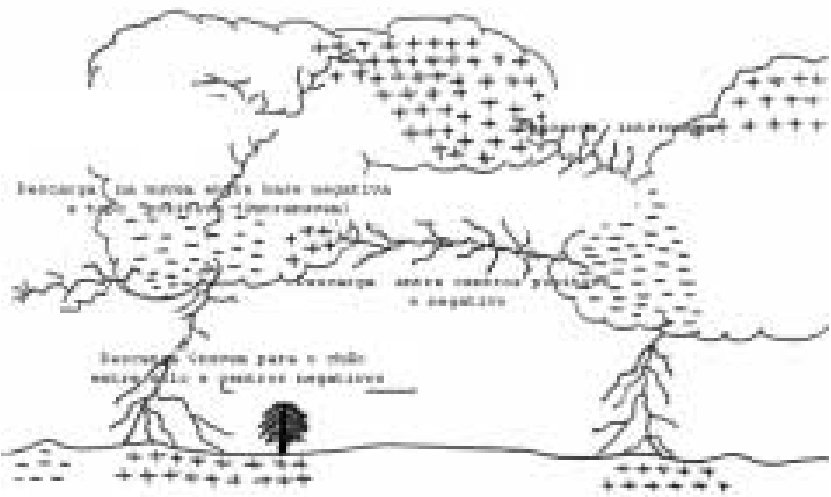

Figura 3. Diversos tipos de relâmpagos observados. No interior da nuvem, ou intra-nuvem, da nuvem para o ar e inter nuvem, que é de nuvem para nuvem, finalmente as descargas para o solo que são as mais conhecidas.

\section{Relâmpago-bola}

Abordamos nesse parágrafo um assunto muito polêmico conhecido no Brasil como "relâmpago-bola" (RB). O fenômeno consiste de esferas luminosas em geral vermelhas ou alaranjadas que aparecem na passagem dos raios entre a nuvem e o solo. Algumas vezes essas manifestações são confundidas e atribuídas a OVNI's. As esferas alaranjadas têm tamanho aproximado de uma bola de basquete e um tempo de vida de cerca de um segundo durante o qual movem-se horizontalmente mantendo luminosidade aproximadamente constante. RBs foram observados no interior de casas e dentro de aviões. Não existe consenso sobre os mecanismos responsáveis por RBs. Até o momento as teorias apresentadas são insuficientes para esclarecer tais eventos. RBs foram presenciados por pequena parte da população. Supunha-se um fenômeno de rara observação mas pesquisa recente mostrou que o número de observadores desses eventos não era menor do que quem relata pontos de impacto de raios. Como tais relâmpagos geralmente duram poucos segundos elas não podem estar muito longe do canal principal. Na verdade o fenômeno pode ser comum porém raramente visto. $\mathrm{RB}$ e fogo de Santelmo são confundidos. O fogo de Santelmo é uma descarga da coroa induzida em objeto pontiagudo por cargas das tempestades. Como o RB, o fogo de Santelmo pode ter forma esférica. Diferente do RB, o fogo de Santelmo fica grudado ao condutor e pode exibir algum movimento ao longo dele. Assim o fogo de Santelmo pode durar mais do que um RB. Algumas características desses relâmpagos são importantes porque muitas vezes podem ser confundidos com o fogo de Santelmo. O fogo de Santelmo pode aparecer na forma oval, mas permanecerá colado ao condutor. Descreveremos algumas características ligados ao fenômeno:

a) Ocorrência: muitas observações de RBs foram feitas durante as tempestades. Muitas vezes os RBs aparecem como efeito simultâneo dos relâmpagos da nuvem para o chão. Esses RBs aparecem há poucos metros do chão. Alguns RBs aparecem perto do chão ainda que não tenham ocorrido descargas elétricas.

b) Aparência: RBs são geralmente esféricos, ainda que existam diversas formas observadas. Usualmente medem de $10-20 \mathrm{~cm}$ em diâmetro. No entanto, relatos confirmam diâmetros que variam de 1 a $100 \mathrm{~cm}$. RBs têm várias cores sendo as mais comuns a vermelha, laranja e amarela. RBs não são excepcionalmente luminosos mas podem ser vistos claramente durante o dia. Supõem- se que mantenham o tamanho e o brilho durante o seu tempo de vida, no entanto não é difícil que ambos mudem.

c) Tempo de vida: em geral RBs têm um tempo de vida de menos de cinco segundos. No entanto, foram detectados RBs com tempo de vida de um minuto.

d) Movimento: em geral se movem horizontalmente com uma velocidade de poucos metros por segundo. Alguns se chocam e são repelidos por objetos sólidos, tipicamente o solo.

e) Calor, som e odor: raramente algum $\mathrm{RB}$ foi descrito como quente. De qualquer forma o RB pode derreter fios de metal. Algumas vezes noticiou-se a emissão de som sibilante. Possuem um cheiro repugnante como enxofre ou oxido nítrico.

f) Atração para objetos e cercas: em geral bolas de fogo podem ser atraídas para fios metálicos e 
quando capturados deslizam pelos fios. Algumas dessas observações se aplicariam ao fogo de Santelmo. Foram detectadas bolas de fogo no interior de um avião.

g) Tipos: Existe mais de um tipo de RB. Por exemplo, RB que gruda a um condutor pode ser diferente daquele que flutua livremente. Não existem teorias que expliquem por que o RB tem tal mobilidade.

Estudos teóricos para esclarecer a possível origem dos RBs concluiram que haveria grande quantidade de energia concentrada em pequeno volume protegida do meio ambiente por um invólucro extraordinariamente estável, ou em outra teoria um fluxo contínuo de energia em um pequeno volume, através da energia proveniente do próprio meio ambiente. Essas teorias indicavam um plasma totalmente ionizado por campos magnéticos ou através de vórtices magnéticos mas que no entanto não ofereciam a e stabilidade observada nos RBs mencionados. Alguns dados apontam os RBs como produzidos pela interferência de microondas no ar. $\mathrm{O}$ valor do campo elétrico próximo da superfície do RB é dado como $3 \mathrm{~V} / \mathrm{m}$. O raio do $\mathrm{RB}$ é dado como $0.14 \mathrm{~m}$. Isso corresponde a um comprimento de onda da microonda de $\lambda=0.56 \mathrm{~m}$. Na natureza, o chão, árvores e superfícies líquidas podem funcionar como paredes da cavidade. Com esses valores conseguimos valores de RBs na natureza bastante razoáveis. Yasui [11], sugere que RBs que aparecem na natureza têm a mesma origem daqueles criados por interferência de microondas em uma cavidade. No entanto, algumas experiências realizadas em 1991 mostraram que havia uma forma de produzir as assim chamadas bolas de fogo através de uma descarga elétrica na atmosfera contendo aerossóis com concentração de etano e/ou metano. Essas bolas de fogo são semelhantes aos RBs que ocorrem na atmosfera. No entanto os cientistas disseram que tornou-se muito difícil simular em laboratório uma bola de fogo de plasma que flutuasse e se movesse por um intervalo de tempo razoável na atmosfera natural por meio de interferência de microondas. Em geral as bolas de fogo de laboratório duraram até alguns minutos mas em geral se dividiam em duas [10]. Provavelmente outros vários processos diferentes podem produzir esferas luminescentes na atmosfera, mas essa explicação atualmente tem se mostrado uma das melhores. Vamos concluir essa seção com uma sugestão de simulação de relampagos em laboratório. Atualmente existem tentativas de simulação de RBs para estudar a formação e efeito de tais relâmpagos na atmosfera. O material utilizado é um forno de microondas e velas comuns de cera. A simulação é muito simples e a explicação teórica é que o plasma do fogo das velas é excitado por microondas mudando a sua forma. Veja a Fig. 4.

Atenção Essas experiências são muito perigosas para leigos. Não são recomendadas a repetição de tais experimentos, pois existe risco de explosões. É estritamente necessário observar tempos de duração para o experimento de forma rigorosa [8],[12],[13],[14]. Esses experimentos tentam mostrar uma conexão entre a existência de plasmas e campos eletromagnéticos envolvidos na formação de RBs.

\section{Sprites, Elves e Blue Jets}

Apenas a partir de 1994 foi possível a publicação de fotografias dos fenômenos descritos abaixo pela equipe científica do Alaska. Explicações cientifícas atuais não respondem todas as perguntas, mas os eventos continuam lá para mostrar aos homens que entre o céu e a Terra existem inúmeros fenômenos ainda inexplicáveis. As últimas pesquisas sobre tais fenômenos atribuem possíveis causas para plasmas ou raios cósmicos. A teoria de plasmas envolvida na explicação desses fenômenos ainda é polêmica e discutida. Os fenômenos acima das nuvens recentemente observados têm sido chamados "sprites" (duendes, numa tradução livre) e "elves" (acrônimo de emissions of light and very low frequency). Os "sprites" e "elves" ocorrem na mesosfera e podem alcançar comprimentos horizontais de mais de $40 \mathrm{~km}$ e não só aparecem acima das nuvens como podem se situar na ionosfera inferior ocupando enorme volume da atmosfera. As imagens dos "sprites" são obtidas através de sistema de vídeo. Vários cientistas têm apresentado boas imagens de "sprites" e "elves". A diferença entre "sprites" é que eles são de coloração vermelho-alaranjada e verticais e os "elves" são de cor vermelha porém dispostos como um disco sobre as nuvens tempestuosas. Alguns cientistas explicam esse fenômeno como descargas elétricas de curta duração que iniciam o processo, sendo provavelmente de natureza química, criando estrutura na mesosfera. Os pesquisadores acham que o relâmpago é capaz de criar um intenso campo eletrostático acima da nuvem na qual aparece o "sprite". Íons e elétrons flutuando na atmosfera são aquecidos por esse campo emitindo vermelho em resposta, ver a Fig. 4. As observações mostraram que os 'sprites' são precedidos de um halo de luz difuso em uma altitude em torno de $70-80 \mathrm{~km}$. O centro do halo está a uma altitude de aproximadamente $84 \mathrm{~km}$, e seu comprimento horizontal em torno de $75 \mathrm{~km}$. O topo das emissões ópticas está a $94 \mathrm{~km}$ e sua base em torno de $38 \mathrm{~km}$. O comprimento dos "sprites" múltiplos situa-se abaixo do halo cerca de $30 \mathrm{~km}$. Se o "sprite" for cilindríco a seção reta seria de cerca de $700 \mathrm{~km}^{2}$. Os blue jets (jatos azuis) são o segundo fenômeno óptico para a alta atmosfera, distinto de "sprites" que são observados acima das nuvens de chuva. Como o nome diz eles são ejeções ópticas no topo das regiões eletricamente ativas das tempestades. Eles se propagam para cima em cones de 15 graus com velocidades verticais de $100 \mathrm{~km} / \mathrm{s}$ desaparecendo em torno de $40-50 \mathrm{~km}$. Possuem uma energia óptica de $4 \mathrm{~kJ}$, energia total de $3 \mathrm{MJ}$ e densidade de energia de uns poucos $\mathrm{mJ} / \mathrm{m}^{3}$. Os jatos azuis não estão alinhados ao campo magnético local.[9] 


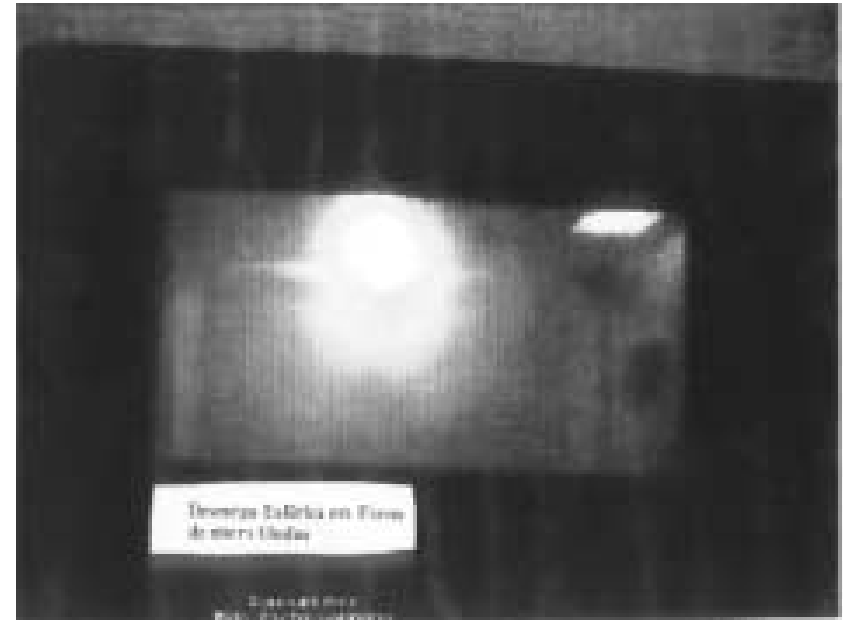

Figura 4. Simulação de um RB em forno de microondas. Essa experiência mostra a ocorrência de uma chama ionizada e através da excitação das microondas, o aparecimento de bolas chamejantes no interior do forno. Na figura o plasmóide é capaz de atravessar o vidro.

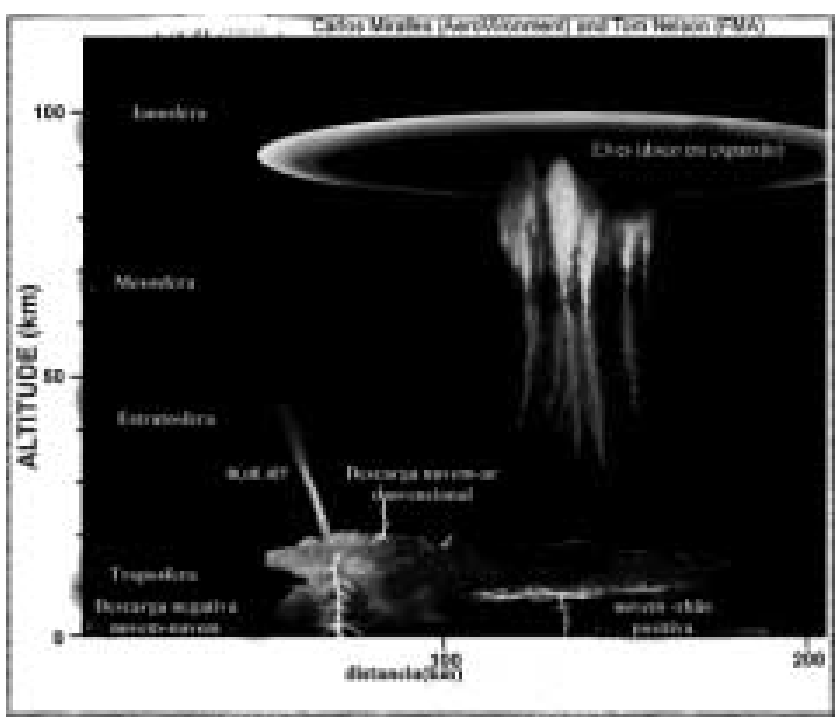

Figura 5. "sprites", "blue jets" e "elves". A figura superior mostra os "elves" e "blue jets" em nuvens de tempestade. A inferior mostra a presença dos três fenômenos juntos na mesosfera.

\section{Por que "Sprites", "Elves" e "Blue jets" não foram ana- lisados antes?}

"Sprites" parecem um mito por vários motivos:

(1) Ocorrem acima de sistemas de tempestades em atividade. A visão dos mesmos requer acesso à região acima da tempestade, não obstruída por nuvens, e tendo contra o campo de visão um céu escuro. Em muitos lugares essas condições ocorrerem raramente.

(2) São tênues e podem ser vistos apenas se os olhos estiverem adaptados à escuridão. Em geral seu brilho pode ser comparado a uma aurora moderada. Eles podem parecer ao olho humano apenas raios luminosos. Por serem tênues, "sprites" não são observados na presença de luzes brilhantes, como achadas na cidade.

(3) A atividade de descargas luminosas pode facilmente distrair o observador que necessita manter os olhos fixos.

(4) Têm duração breve de apenas uns poucos 3-10 ms.

Intensos esforços têm sido feitos para determinar a extensão total desse fenômeno e a partipação do mesmo na eletricidade do meio ambiente terrestre. Existe interesse em saber os possíveis efeitos eletroquímicos de "sprites" e "jets" na mesosfera e estratosfera, respectivamente. A maioria dos modelos para explicar esse fenômenos fornece como fonte de energia os campos elétricos associados com os relâmpagos - os campos quase estáticos devido à distribuição de cargas originais, o pulso eletromagnético devido à propagação do relâmpago de retorno ou o campo quase eletrostáticos devido á redistribuição de cargas na atmosfera por correntes. Os modelos mostram que o aquecimento da atmosfera neutra por esses campos elétricos. Os modelos explicam que por esse meio os elétrons térmicos no meio ambiente acelerados em alta energia ou que raios cósmicos geram elétrons com Mev de energia. Esses elétrons aquecidos por colisões aquecem os neutrons e produzem, calor, ionização e emissões ópticas observadas [15].

\section{Conclusões}

Os fenômenos acima fazem parte do circuito elétrico atmosférico global da Terra e envolvem partículas ionizadas significando existência de plasma nesses eventos. Essas correntes de ar ionizado situadas no circuito global têm diversos nomes e são estudadas por satélites ou por instrumentos situados em diversos pontos do globo terrestre. Os efeitos descritos acima fazem todos parte desse circuito global. Descrevemos parcialmente os fenômenos apresentados. No entanto até o presente momento não existe nenhuma teoria que explique totalmente esses eventos. O importante na observação de todos os fenômenos descritos acima é que eles não estão totalmente explicados à luz da ciência. Mesmo os relâmpagos em algumas circunstâncias permanecem fora do entendimento dos pesquisadores.

\section{Referências}

[1] Tavares M., Aprendendo sôbre o Sol, Rev. Bras. Ens. Fis., 22 (1) 78, (2000).

[2] Tavares M., Theoretical plasma model for intracloud lightning, Proc. of the VI Brazilian Workshop on Plasma Physics,Campos do Jordo, pg.260,2001 
[3] Lyons W.A, Lightning in: Pielke, R. Jr., PielkeR, ed Storms., Vol II., London, Routledge,p 60-79, 1999.

[4] Lyons, W.A., Armstrong R.A., Bering E.A III, Williams E.R. The hundred year hunt for the sprite EOS Transactions, 81(33):373-375, agosto 2000

[5] M.A. Uman, Lightning, Library of Congress Cataloging in Publication Data, (1984).

[6] M.A. Uman, All about Lightning, Dover Publications Inc., New York (1986).

[7] Gish O.H., Wait G.R., Thunderstorms and the Earth's General Electrification, Journal of Geophysical Research, 55, no. 4, (1950).

[8] http://sprite.gi.alaska.edu/html/.htm- Red Sprites and Blue Jets.

[9] Stenbaeck-Nielsen H.C, Moudry D.R., Wescott E.M., Sentman D.D and Sabbas F.S Sprites and Possible me- sospheric effects, 124-134 Geophysical Research Letters, (2000).

[10] Ohtsuki Y.H. and Ofuruton H. Plasma fireballs formed by microwave interference in air, Nature, 350, 139 (1991).

[11] Yasui K., Plasma fireballs fed by microwaves, Phys. Lett. A 173, 451 (1993).

[12] http: //members.tripod.com/ hochwald/microwave/ball.html

[13] Williams E.R., Science 256, 1184 (1992).

[14] Tsui K.H., Force - Free Field Model of Ball Lightning, Phys. Plasmas 8, 687 (2001).

[15] Rowland H.L , Theories and simulations of elves, sprites and blue jets, J. Atmosphere and Solar-Terrestrial Physics, 60, 831 (1998). 